\title{
Explorations into Starch Properties of Mirabilis spp. (Nyctaginaceae); DSC Results for Endangered Andean M. expansa, TEM of M. jalapa Seed
}

\author{
Miriam S. Kritzer Van Zant ${ }^{1 *}$, Kanokporn Triwitayakorn², David A. Lightfoot ${ }^{1}$ \\ ${ }^{1}$ Department of Plant, Soil and Agricultural Systems, Southern Illinois University, \\ Carbondale, IL 62901-4415, USA \\ ${ }^{2}$ Center of Excellence on Agricultural Biotechnology: (AG-BIO/PERDO-CHE), Bangkok, 10900, \\ Thailand and Institute of Molecular Biosciences, \\ Mahidol University, Salaya, Nakhorn Pathom, 73170, Thailand
}

Received Date: March 12, 2020; Accepted Date: March 25, 2020; Published Date: April 03, 2020

"Corresponding author: M Kritzer Van Zant, Department of Plant, Soil and General Agriculture, Southern Illinois University-Carbondale, Carbondale, IL, USA. Email: mkvzant@gmail.com

\section{Abstract}

Explorations into the starch properties of two species of Mirabilis (Nyctaginaceae) was the focus of preliminary research. Andean Mirabilis expansa (Ruiz and Pav.) Standl. includes the wild type, and an endangered, indigenous crop derived from it. No varieties of the crop are known to be patented or in commercial use. Mexican M. jalapa L. has been manipulated horticulturally since pre-Columbian times, is grown internationally for its flowers today, and is also known as a weed throughout the topics. Differential Scanning Calorimetry (DSC) was applied to starch derived from both lyophilized and air-dried material from two varieties of $M$. expansa, for this study. $M$. expansa starch samples from both varieties, submitted for DSC, were extracted from above and below ground rhizomes, roots and stems, that were enlarged with material stored by growing plants. Transmission Electron Microscopy (TEM) was used to examine seed starch from M. jalapa. Starch from both M. expansa varieties was shown to be competitive with cassava starch in the DSC study. Lyophilized material contained considerably more of the starch than air dried pieces of the same type. In addition, TEM of $M$. jalapa seed, revealed starch granules consistently 1-2 $\mu \mathrm{m}$ in diameter. The need to develop the crop, improve protection for ancient crop varieties and the wild type, breed new disease resistant varieties, and for research on the starch's food and commercial potential, is also considered. Included is our perspective on issues surrounding funding for further research on $M$. expansa, and for other indigenous crops with no previous history as modern crops.

Keywords: Almidón; Cultivos Indígenas; DSC; Indigenous Crops; Mirabilis expansa; M. jalapa; Nyctaginaceae; OSSI; Plant Genetic Resources; Recursos Fitogenéticos; Starch; TEM

\section{Introduction}

Mirabilis expansa L. (Ruiz and Pav.) Standl. (Nyctaginaceae) was developed into an indigenous crop in the Andes [1, 2]. Its true origin is still obscure. $M$. expansa has become very rare in Andean, indigenous, traditional agriculture [1-3]. Only sufficient $M$. expansa material was available for DSC (Differential Scanning Calorimetry), of each sample submitted for starch testing at the time of this research. M. expansa material for DSC was grown in Southern Illinois [4]. DSC results are the core of the Results section of this note. 
While examining microscope slides of cross sections of the roots of $M$. expansa agricultural varieties $L$ and $T$, Kritzer Van Zant noticed a considerable amount of what appeared to be starch saturated tissue. On the advice of Donald Ugent, it was decided that anthropological starch techniques might yield a valuable taxonomic character. Ugent had pioneered methods for using starch grains to identify potatoes to variety, and other starchy roots, in both fresh and archaeological remnants $[\mathbf{5 , 6}$. These methods require a series of steps, including staining starch granules while examining them under plain polarized light on a standard microscope. As starch grains of M. expansa were too small to see individually under a standard microscope, even at 1,000x, it was not possible with equipment available for our use at that time, to use Ugent's starch identification techniques.

Prior to obtaining living M. expansa material, Kritzer Van Zant made TEM (Transmission Electron Microscopy) images of $M$. jalapa L. seed starch (Figure 1). M. jalapa seed starch was also too small to distinguish at 1,000x magnification. TEM of $M$. jalapa seed revealed oval starch granules, typically 1-2 $\mu \mathrm{m}$ in length (Figure 1). Chang et al. characterized M. jalapa seed starch as 1.5-3.0 $\mu \mathrm{m}$ in size [7]. Four Andean indigenous crops have all been shown to have larger starch grains than those seen for Mirabilis; they were imaged at less than 1,000x with SEM (Scanning Electron Microscopy) [8]. Starch grains were shown to be 9-38.2 $\mu \mathrm{m}$ for Oca (Oxalis tuberosa Molina), 4.48-24.9 $\mu \mathrm{m}$ for Olluco (Ullucus tuberosus Loz), 4.45-22.9 $\mu \mathrm{m}$ for Isaño (Tropaeolum tuberosum (Ruiz \& Pav.) Standl.), and 5.36-23.8 $\mu \mathrm{m}$ for Arracacha (Arracacia xanthorrhiza Bancroft) [8]. If the M. jalapa seed starch size reported in the Results section below, is typical for the genus, the largest Mirabilis seed starch granule was nearly half the size of the smaller grains reported for Olluco or Isaño starch [8].

Starch particle sizes have also been established for other tropical tubers. For the following crops, the ranges given represent smallest to typical size of starch particles. Some of these sizes were given in text [9], and some estimated by us from graphs [9]. The lengths for these Indonesian traditional tuber starch grains are 17-345 $\mu \mathrm{m}$ for yam (Dioscorea alata L. var. Krimbang), 2-315 $\mu \mathrm{m}$ for taro (Colocasia esculenta (L.) Schott var. Bentul), 6-10 $\mu \mathrm{m}$ for cassava (Manihot utillisima Pohl var. Muntilan), 19-288 $\mu \mathrm{m}$ for sweet potato (Ipomoea batatas (L.) Lam. var. Kalasan), 53-316 $\mu \mathrm{m}$ for canna (Canna edulis Ker Gawl. var. Ganyong merah), 8-27 $\mu \mathrm{m}$ for arrowroot (Marantha arundinaceae L. var. Creole), and 27-378 $\mu \mathrm{m}$ for konjak (Amorphophallus campanulatus Blume ex Decne. var. Mutiara) [9]. The smaller starch grains for taro were in the same size class as those of $M$. jalapa seed starch. However, these smaller sized grains in taro were not a large percentage of the total starch [9], as they are so far known for $M$. jalapa seed starch. Indonesian cassava starch grains [9], were 2-4 times longer than M. jalapa seed starch grains, as measured either in our work in the Results section below, or in work by Chang et al. [7].

Both SEM and TEM require that samples are fixed, usually by embedding them in a clear resin. Fixed samples are then thinly sliced, to allow photons to pass through the material during imaging. Fixed material cannot be utilized for most anthropological starch techniques since these techniques require viewing changes to cellular tissue while applying stains under plane polarized light. The minute size of Mirabilis starch grains may be why we were unable to find a record of it from microscopic studies of Latin American anthropological materials [1].

Though we have yet to obtain SEM or TEM pictures of $M$. expansa starch, some material left over from growth experiments with M. expansa in southern Illinois was sent to Mahidol University in Thailand for starch analysis by Triwitayakorn. This Thai lab usually works on cassava starch. Cassava is an important carbohydrate for more than 500 million people [10, 11]. Lightfoot has pointed out that in many cases; cassava is grown for export from regions where food is scarce. M. expansa is grown in arid regions, while cassava is usually grown in wet areas. It is possible that starch from M. expansa and/or other Mirabilis spp., can fulfill at least some of the uses of cassava starch, increasing the potential for growing larger amounts of more nutritious food for local use, in some areas currently under cassava production. Don Ugent had also commented that very fine starch is important for rehydration of famine sufferers, as finer starches are easier for stomachs to keep down after an extended period of no food.

We have demonstrated that two varieties of M. expansa are protein machines, producing large amounts of complete protein and additional amino acids, and discussed possibilities for separating the starch and protein from the oxalate crystals found throughout these plants [1, 12]. Further investigation is also needed into a class one ribosome inhibitor found in the crop, thought to only affect insects and microbes $[13,1]$. Starch rich roots of M. expansa were mixed with other roots and eaten by humans in the Andes, while the leaves provided fodder for domesticated animals [1]. M. jalapa starch has been used for specialized purposes in Japanese baking [7].

Two batches of soup, each containing a small M. expansa root, were cooked by Kritzer Van Zant until the M. expansa roots completely dissolved into the broth, which gained a silky feel. The $M$. expansa starch stayed in suspension when the soups were left out overnight, unlike most starch containing liquids. We believe the starch remained in suspension in these soups, due to the minute size of Mirabilis root starch grains. This may indicate additional commercial potential for Mirabilis.

In addition, recent research has shown that a number of root crops that contain a large percentage of starch are good candidates for bio-fuel production, including $M$. expansa [14]. It may be that using Mirabilis spp. starch to produce renewable fuel is another avenue worth exploring. Mirabilis starch may also prove useful to malt to produce a new gluten free sweetener, and may also be a new source material for alcohol production for non-biofuel purposes. However, any use of M. expansa or other Mirabilis spp. for consumption, 
whether by animals or humans, requires testing to make sure that methods of removal or remediation of oxalate crystals are consistently successful. These crystals are prevalent throughout all tissues of Mirabilis examined by us. The unique enzyme inhibitors in Mirabilis also need to be examined for food safety. Judicious application of international law is also needed, to protect the rights of indigenous people whom have developed and or maintained ancient $M$. expansa as a crop and of nations to limit the use of their natural resources. There needs to be balance between these rights and the possibility of funding needed research on any crop, particularly crops like $M$. expansa, facing imminent extinction, and lacking any commercial varieties already in use for modern agriculture. It would be unfair to future generations, indigenous and those of other people, to allow a plant with this much promise to go extinct, while these issues continue to be reconsidered.

\section{Experimental Section}

\section{Materials}

M. expansa varieties $L$ and $T$ were grown as described in Kritzer Van Zant et al. [4]. All plots used to grow this material contained 96-100\% sand. The plot types contained several combinations of soil amendments. Amendments consisted of percentages of peat, steer manure, a combination of both, and for var. $L$ and all sand control [4].

M. expansa material used for DSC was stored in a $-80^{\circ} \mathrm{C}$ freezer for several years prior to beginning the starch research. Plant material had been harvested when plants were about three-months of age. At harvest, they were processed for storage at $-80^{\circ} \mathrm{C}$. Some of the material had been lyophilized prior to being frozen, some had been frozen after air drying up to a month, without lyophilization. Each sample had material from all of the plot types used to grow each variety. Lyophilized DSC samples were kept separate from DSC samples that were frozen without lyophilization. Root material was also separated from above ground growth. Therefore, eight samples were sent to Thailand, four of each variety. Root material was expected to yield considerable starch. Combined stem and leaf material was examined to see if it also contained high amounts of starch. The stem material used for this was not very obviously engorged with starch. M. expansa sometimes produces high levels of starch in stems as well as in rhizomes, particularly in the crown region which is mostly below the soil, and just above the ground nearest to the crown.

M. expansa samples sent to Thailand were numbered and weighed as follows:

\#1 var. $L$ lyophilized root (included some enlarged stem) $26.1 \mathrm{~g}$

\#2 var. $T$ lyophilized root $28.7 \mathrm{~g}$

\#3 var. $T$ air dried stem/leaf $5.0 \mathrm{~g}$

$\# 4$ var. $L$ air dried stem/leaf $40.2 \mathrm{~g}$

\#5 var. $L$ lyophilized stem/leaf $28.5 \mathrm{~g}$

\#6 var. $T$ lyophilized stem/leaf $5.0 \mathrm{~g}$

\#7 var. $L$ air dried root $11.3 \mathrm{~g}$

\#8 var. $T$ air dried root $5.3 \mathrm{~g}$

\section{Methods}

\section{Starch Extraction}

Lyophilized and air-dried starchy storage roots and rhizomes of varieties $L$ and $T$ of $M$. expansa, which had been stored at $-80^{\circ} \mathrm{C}$, were weighed to $5 \mathrm{mg}$ or more per sample and sent to Thailand for analysis. In Thailand, $M$. expansa starch of each variety was extracted, using water as the extraction solvent. A laboratory blender was used to break up root tissues, resulting in the release of starch granules $[\mathbf{1 5}, \mathbf{1 6}]$. The blended slurry samples were sieved through cloth to collect the starch. The residue of each sieved sample, was mixed with water, then filtered again, then filtrates were pooled for each sample. To remove fiber from the residue, the combined filtrates were passed through a $90 \mu \mathrm{m}$-mesh screen. Starch was first collected by allowing it to settle for $12 \mathrm{hrs}$. Settled starch was then washed with water and allowed to stand for $4 \mathrm{hrs}$ more, to remove soluble protein. Soluble starch was next air dried for $12 \mathrm{hrs}$, then oven dried at $55^{\circ} \mathrm{C}$ for $48 \mathrm{hrs}$. The dried starch samples were ground into fine particles using a mortar and pestle, and passed through a 100-mesh sieve prior to DSC analysis. No additional efforts were made to remove or reduce oxalate crystals.

\section{Differential Scanning Calorimetry (DSC)}

There was only sufficient material of each sample, after starch was extracted, for DSC (Differential Scanning Calorimetry) analysis. A chart of the DSC output is given below (Figure 2). In the chart (Table 1), the word integral represents the area enclosed by the DSC peak, which is the energy used to melt a starch sample. Integral is designated with a question mark in front of it, in the graph (Figure 2). The question mark has no additional meaning except that the integral has not been normalized. The integral is given in $\mathrm{mJ}$ 
(millijoules), prior to normalization. The normalized integral is the energy used to melt a single unit of starch, in this case, to melt $1 \mathrm{~g}$ of starch. Normalized curves have been converted with the initial heat capacity as the reference (Figure 2). Therefore, normalized curves take heat capacity into account.

The peak is integrated, to obtain the enthalpy of that particular transition or change. Negative peaks are exothermic transitions, and positive peaks would be endothermic transitions. The transitions denoted in any DSC results are all exothermic, so all graphs produced point downward (Figure 2), and are negative. The peaks indicate the temperature for starch pasting. Onset, Peak and Endset are given in ${ }^{\circ} \mathrm{C}$ (Figure 2). Units are given in millijoules ( $\mathrm{mJ}$ ) and $\mathrm{Jg}$ are joules/gram (Figure 2). In Figure 2, \% w/w is the percentage of starch suspended in water and used as the DSC samples, after they have been dried, ground and passed through a 100-mesh sieve.

\section{Results and Discussion}

TEM of M. jalapa starch

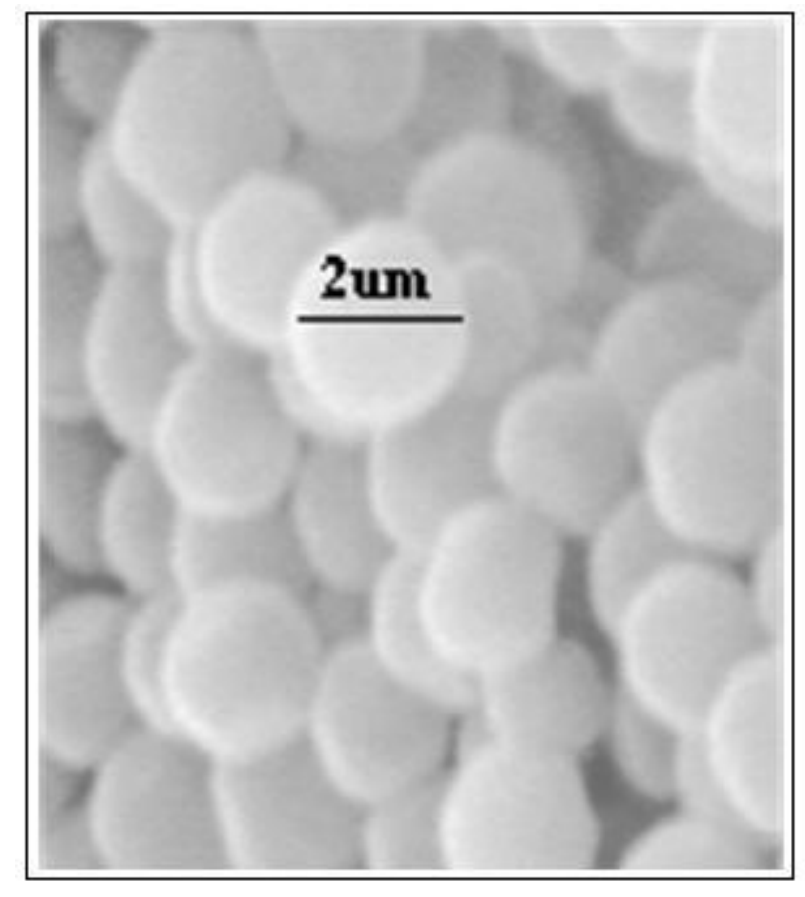

Figure 1: TEM of Mirabilis jalapa L. Seed Starch.

Figure 1 shows Mirabilis jalapa L. seed starch granules 1-2 $\mu \mathrm{m}$ in diameter. $M$. jalapa seed starch granules are spherical to slightly ovate, and unlike some starch grains appear to have no angularity to their shape. It may be that Mirabilis root and/or stem starch granules can get larger, especially as plants can be biennial or perennial. However, we were not able to image individual starch grains for any Mirabilis starch, including M. expansa and M. jalapa, at 1,000x magnification under standard light microscopes, from herbarium or fresh material.

In the DSC chart (Figure 2), the raised carat " $\wedge$ " indicates "to the power of", so "g^-1" is "per gram" and refers to the gelatinization temperature (GT) of starch. DSC output therefore relates in part to RVA pasting temperature (PT).

The range of Onset temperatures for the melting of $M$. expansa starch is $60.70-63.61{ }^{\circ} \mathrm{C}$, and Endset temperature ranged from 72.95-77.36 ${ }^{\circ} \mathrm{C}$. The Peak temperature for gelatinization of the starch ranged from $66.24-70.06^{\circ} \mathrm{C}$.

Dr. Triwitayakorn was the primary person to interpret the DSC chart. The small amount and low quality of starch obtained were the reasons that only DSC could be used for analysis and the low quality contributed to the small size of the striped areas of the graphs (Figure 2). DSC evaluates how much energy is used to melt the starch granules. The lines in the graph (Figure 2) begin where the first granule started to melt when high temperature was applied. Sample numbers 1,2, and 5 yielded starch of high enough quantity and quality to clearly read the results. Samples 1, 2 and 5, were all lyophilized. They consisted of root material for both varieties, and stem/leaf for var. $L$. The only lyophilized sample that did not yield enough starch for an easy read was sample \#6, which consisted of stem/leaf starch for var. $T$. Sample \#6 was one of the samples with poorly purified starch (see below). 
There are three possible reasons in addition to poorly purified starch, which may explain why only var. $T$ stem/leaf of the lyophilized samples did not yield good results. One is that this difference is due to variety. However, a single sample of each is not enough to be certain that variety made a difference in quality and quantity of stem/leaf starch. Two is that the other three lyophilized samples consisted of more than 25 grams of raw material, where the lyophilized var. $T$ stem/leaf sample was only $5 \mathrm{~g}$ to begin with. It may be that the team in Thailand either added extra raw material for samples for which more material was available, or that they were able to select the most promising material when standardizing the amounts from the larger samples. The third reason may be that of the two lyophilized stem/leaf samples, only one had stored much starch. This is in keeping with the way M. expansa stores starch, concentrating it primarily in the roots, and at least in the greenhouse, varying the expansion and contraction of the stem diameter above the soil line and crown of the plants, through time, for what appeared to be stored material. This expansion and contraction was particularly obvious in stock plants that had been maintained for several years in the greenhouse. At one point, the expanded areas of the stems of two stock plants appeared like a series of spheres, similar to a string of pearls. However, this spherical pattern was unusual and did not persist for more than a few weeks. Usually the expansions had no special pattern. This contraction and expansion of stems also appeared to have had little to do with which variety was involved.

\begin{tabular}{|c|c|c|c|c|c|c|c|c|}
\hline $\begin{array}{c}\text { Var. } \\
\text { Part/Drying }\end{array}$ & $\begin{array}{c}L \\
\text { stem/lf lyophil }\end{array}$ & $\begin{array}{c}L \\
\text { stem/lf air }\end{array}$ & $\begin{array}{c}T \\
\text { stem/lf lyophil }\end{array}$ & $\begin{array}{c}T \\
\text { stem/lf air }\end{array}$ & $\begin{array}{c}L \\
\text { root lyophil } \\
\end{array}$ & $\begin{array}{c}L \\
\text { root air }\end{array}$ & $\begin{array}{c}T \\
\text { root lyophil } \\
\end{array}$ & $\begin{array}{c}T \\
\text { root air }\end{array}$ \\
\hline Sample \# & 5 & 4 & 6 & 3 & 1 & 7 & 2 & 8 \\
\hline g raw & 28.5 & 40.2 & 5 & 5 & 26.1 & 11.3 & 28.7 & 5.3 \\
\hline mg starch & 12 & 12 & 11.5 & 13.2 & 13 & 12 & 12.1 & 14 \\
\hline w/w \% & 33.3 & 28.6 & 22.2 & 25 & 33.3 & 33.3 & 33.3 & 25 \\
\hline ?Integral $\mathrm{m}$ & -27.07 & $\mathrm{NA}$ & -6.5 & NA & -42.13 & -4.91 & -35.13 & -2.81 \\
\hline $\begin{array}{c}\text { normalized } \\
\mathrm{Jg}^{\wedge}-1\end{array}$ & -2.26 & NA & -0.56 & NA & -3.24 & -0.41 & -2.9 & -0.2 \\
\hline Onset ${ }^{\circ} \mathrm{C}$ & 61.45 & NA & 63.61 & NA & 60.7 & 62.23 & 61.29 & 63.11 \\
\hline Peak ${ }^{\circ} \mathrm{C}$ & 68.25 & NA & 67.94 & NA & 68.88 & 69.27 & 66.24 & 70.06 \\
\hline Endset ${ }^{\circ} \mathrm{C}$ & 77.36 & NA & 72.95 & NA & 76.36 & 73.57 & 74.01 & 75.8 \\
\hline
\end{tabular}

Notes for Table 1: Table 1 clarifies the words seen in Figure 2. The material examined represents above and below ground growth after a single season outdoors in sand plots in southern Illinois. Delta-H for the graphs represents the integral and designates all of the energy used to melt the starch (Figure 2), Onset, Peak and Endset together form Delta-H which is the striped areas or area under the curve.

Terms and Abbreviations: Air, is air dried; Endset, is the temperature in ${ }^{\circ} \mathrm{C}$ when the starch sample finishes melting; $\mathrm{g}$ raw is the weight of each sample sent to Thailand; ?Integral (Figure 2) means the integral, which designates the energy used to melt the starch, measured in $\mathrm{mJ}$; lyophil is lyophilized; $\mathrm{mg}$ starch is the weight of the dry starch sample prior to suspending it in water for DSC; mJ is millijoules; normalized, is the integral normalized per 1 gram of starch, utilizing the heat capacity as the reference; Onset, is the temperature in ${ }^{\circ} \mathrm{C}$ when the starch begins to melt; Peak, is the starch pasting temperature seen at the bottom of the striped areas (Figure 2); w/w\%, is the percentage weight of a starch sample that has been suspended in water for DSC.

Table 1: Chart of DSC results for starch from M. expansa (Ruiz and Pav.) Standl.

Details are given (Table 1) of the information shown in the image of the DSC printout for M. expansa varieties $L$ and $T$ (Figure 2).

Sample \#1, consisted of lyophilized var. $L$ root starch which began to melt at $60^{\circ} \mathrm{C}$, with all starch granules melted at $77^{\circ} \mathrm{C}$. For most of the other samples, starch granules melted at $68^{\circ} \mathrm{C}$.

Samples \#3 and 4 were not good starch samples. These were air dried leaf and stem samples of each variety. As the air-dried samples generally produced less starch than lyophilized samples, it may be that much of the starch broke down during air drying. The plants may have actually done this to try to extend the life of their cells, especially as the plants were air dried intact, then separated into above/below ground portions after drying. If the starch really does break down during the drying process while tissues are still alive, lyophilization appears to be a good way to preserve the starch content.

Sample \#5, which consisted of var. $L$ stem/leaf starch, had the largest temperature range from Onset to Endset, indicating variation in starch granule size, which resulted in longer times and higher temperatures for starch to completely melt. However, Delta-H, the area under the curve, was smaller for sample \#5, compared with the two lyophilized root samples, samples \#1 and 2, suggesting there was more amylose in sample \#5 than in samples \#1 and 2. 


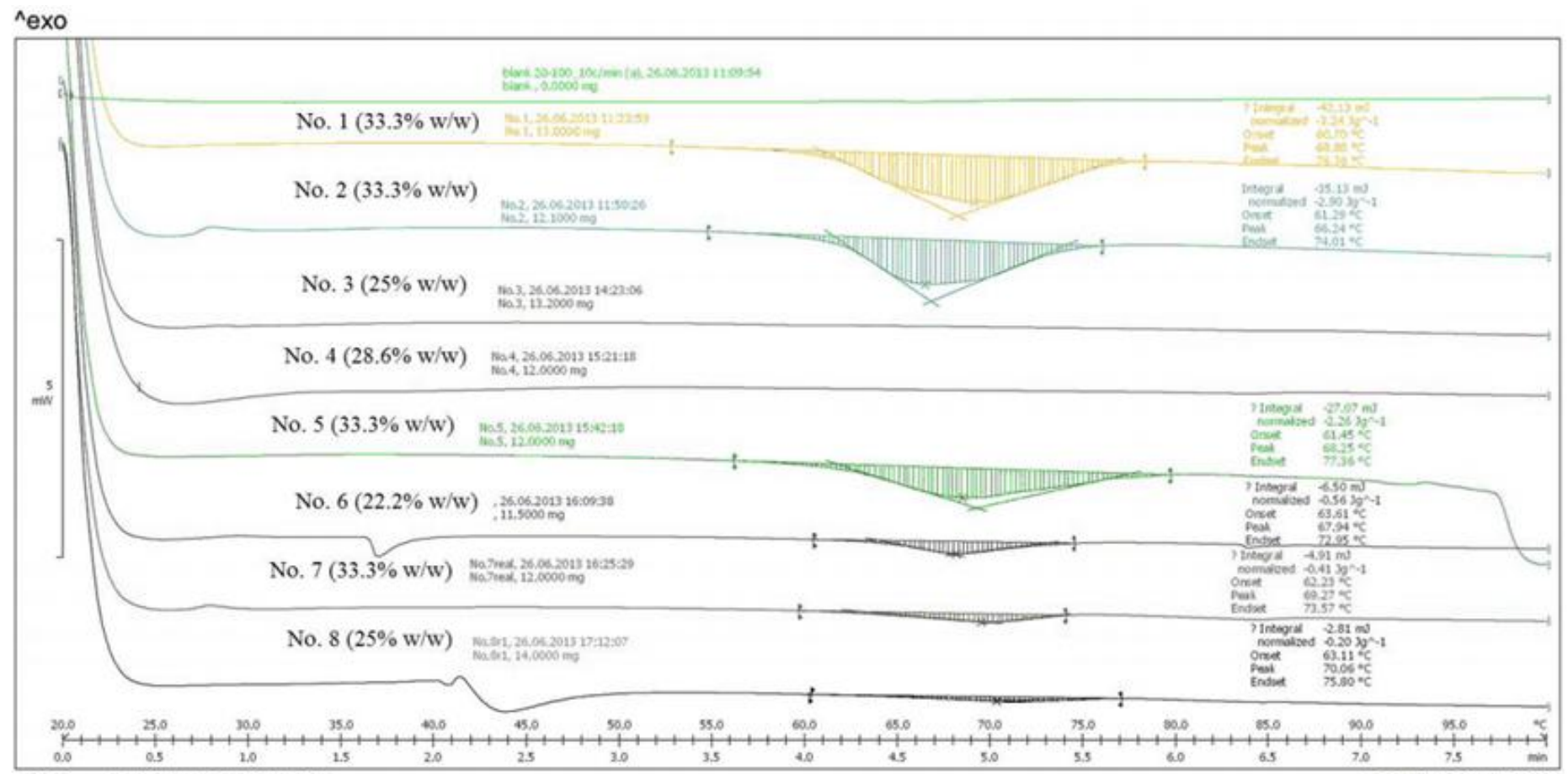

BioTec Mahidol: METTLER

Figure 2: DSC for starch from M. expansa (Ruiz and Pav.) Standl. grown in southern Illinois.

Samples \#6, 7, and 8 had very low peaks, probably due to the impurity of the starch. Perhaps these impurities are the high levels of oxalate crystals. Samples \#7 and 8 were the air dried root samples of both varieties. Sample \#6 was the lyophilized stem/leaf sample of var. T, discussed above. However, samples \#6 and 7 showed a small range of temperature for the starch to melt, also called gelatinization, and this might be due to these samples having more homogeneity of starch granule size than other samples. Sample \#7 consisted of starch from the air dried root of var. $L$.

\section{Conclusions}

M. expansa starch offers promise as a food source in the manner of cassava and arrowroot starch. Donald Ugent has pointed out that small starches are particularly useful for famine relief products, as smaller starch granules are easier to digest than larger ones. This is especially important when a patient is having trouble keeping foods down. Mirabilis starch may also prove useful for dysphagia patients, who have difficulty swallowing thin liquids, including some persons recovering from strokes. There are already starch products on the market for this purpose. Smaller starch grains should dissolve into solution in water better than larger ones, making it faster and easier to mix these types of products. The ability of $M$. expansa's minute starch granules to stay in solution may give them additional commercial potential for keeping products in suspension, including ketchup and whipped foods, as well as cosmetics and paints. Currently, many commercial foods including cream pies and whipped cream are kept in suspension with acrylamide, a known nerve toxin and potential mutagen.

To determine starch pasting properties for M. expansa and other Mirabilis spp., will require growing sufficient material for larger samples needed for RVA (Rapid Visco Analyzer). RVA should be done when both more material and funds are available. RVA requires at least $3 \mathrm{~g}$ of purified starch per sample. There was insufficient southern Illinois $M$. expansa material left over from the growth experiments to obtain sufficient amounts of starch for RVA, at least not without combining all that was tested separately by DSC. This would have made a single sample to represent the species. The M. expansa pieces from which starch was extracted for DSC were not those containing the highest levels of starch, as those pieces had already been used in earlier research for the protein profile and food safety exploration [12]. With RVA it would have been possible to get the PTi (Pasting Time), PV (Peak Viscosity), HPV (Hot Paste Viscosity), CPV (Cool Paste Viscosity) and PT (Pasting Temperature). From these values, the derivative parameters Breakdown $(\mathrm{BD}=\mathrm{PV}-\mathrm{HPV})$ and Setback $(\mathrm{SB}=\mathrm{CPV}-\mathrm{PV})$ could also have been determined. However, Onset/Peak/Endset from the DSC together address the gelatinization temperature (GT) of starch. So they do relate in part to RVA PT. Mettler personnel pointed out that PTs tend to overestimate GT, due to the high rate of heating used. Therefore, they suggested using the gel temp method to further study gelatinization. 
The extremely minute size of Mirabilis starch indicates the starch may be of both nutritional and industrial value. Anecdotal experience with cooking the roots are what indicated that $M$. expansa starch of both varieties has the ability to stay in aqueous solutions overnight. However, more experiments are needed to confirm this property, and to learn how long the starch can stay in suspension. It remains to be seen if $M$. expansa material originating from Ecuador and Peru will be allowed in biofuel research, according to limits set by international law and the terms under which two varieties of $M$. expansa were released by CIP (Centro Internacional de la Papa) and Ecuador, for Kritzer Van Zant's research. There are other new world Mirabilis spp., including north American species of Mirabilis, which may also prove valuable for biofuel research, to make sweetener and produce alcohol, and to incorporate in breeding new varieties of the crop.

We hope that those working on international treaties for sharing economic plant resources, recognize the differences, between endangered traditional crops like M. expansa, with few varieties left in traditional cultivation, and no varieties available commercially, and traditional varieties of widely grown crops for which economic investment is well established, and for which many commercial varieties are already available to breeders and for other research, when setting up limits on research that may result in commercial success. It is rightful to reward the originators of a crop and/or those who have protected it through their traditional agricultural practices. However, funding available to do needed work is often tied to those areas most likely to have international limits, including genetics, pharmaceutical, chemical, and biofuel research. This is additionally difficult with a species like M. expansa, as its true origin is not known, complicating the question of who has a right to patent traditional crop varieties. Due perhaps to imperialistic practices, including those of the Incan empire, and those since its demise, it is not known if those few who still grow M. expansa today are the descendants of the true originators of the crop. They may be. It is also possible that different groups of Andean people brought the crop and/or certain crop varieties into existence, independently of each other. It is also not known if any of the few remaining traditional growers continue to develop the crop for disease resistance. However, they are due some compensation for keeping the crop alive, should any significant economic gain be realized from these plants. This will only be possible if their varieties are included in future funded research on Mirabilis, that succeeds in developing new varieties and/or marketable products.

Most research of any kind does not result in economically useful results. Therefore, it is always a gamble to invest in any kind of research. Economic gains from the crop as a result of modern research should reward both ongoing modern research efforts, and past and continuing traditional efforts to develop and maintain the crop. Rewarding both fairly greatly increases chances that the crop will remain available to future generations. It will be as much their rightful legacy as it is of people living today. This will require economic investment in both research and development of Mirabilis which we hope will include M. expansa. Then, this ancient crop can become a modern boon, while remaining a boon to its indigenous growers and their offspring. To accomplish this, safety research on oxalate removal and remediation, and with the unique enzyme inhibitors found in Mirabilis spp., as well as developing commercially viable new varieties and products, is needed. New varieties have to be developed to allow any crop to survive changing environmental conditions and the influx of new forms of bacteria, fungi and viruses that may attack a crop.

The focus has been for well-funded researchers to have input on how to best design the limits of who gets what. There needs to be opportunity included for researchers who are outside the mainstream trends in science, to be able to fund needed research on old crops. These researchers are more likely to be willing to work on something that is not yet a sure thing. As there is currently very little money for plant breeding of any kind, the door needs to remain open to do the kind of research on traditional crops plants that will allow researchers to pay both their research and personal bills, and to allow their students and employees to do the same. This is what is realistically needed to continue research for any traditional crop. Otherwise, research to identify old crops may only be creating footnotes on useful organisms soon to be extinct.

Sociologist Jack Kloppenburg, one of the designers of Open Source Seed Initiative (OSSI) [17], has noted that some of the early OSSI ideas for protecting crop varieties, need to be reconsidered in the wake of shrinking funding for plant breeding, including the need for a royalty bearing option for plant breeders, at least in North America [18]. It would seem if North American researchers are allowed royalty options, other researchers around the world will expect equal treatment. OSSI commitments currently require that indigenous varieties of crops, and also varieties developed from them, be pledged for no patents [17]. Kloppenburg's royalty option makes sense for new varieties developed at least in part from indigenous varieties. This is particularly true for a crop like $M$. expansa. Unlike soy, rice, broccoli or even crops still seen as traditional such as breadfruit, there are so far no commercial varieties available to breeders for M. expansa, and only a few surviving highly endangered varieties of the crop remain in existence.

For now, M. expansa is not on the Annex I list, so does not qualify for the FAO (Food and Agricultural Organization of the United Nations) treaty that CIP currently requests research institutions sign on to. That treaty limits research for non-agricultural purposes. We hope that M. expansa remains off the Annex I list, and that when appropriate, restrictions on collection permits, for future research with material from developing nations including Ecuador, can be adjusted or renegotiated for the realities of financing useful research on traditional crops today, as appropriate on an individual case basis, for each species to which this applies.

It should further be considered that the wild types of $M$. expansa may also be endangered. These plants disappear underground in droughts, and rot out easily in standing water, and can therefore be difficult to find and therefore to assess their status. The details on 
what is allowed for old crop research should continue to take into consideration the concerns of traditional people that developed and/or maintained these crops, yet not slam the door on what is needed to keep these species, and the thousands of years of human development on them, extant. These crops were often developed by multiple groups of traditional people, making it difficult to identify which indigenous group has the legal right to patent particular varieties, let alone new varieties developed with their germplasm.

CIP's efforts to keep seed collections of $M$. expansa have been thwarted to some extent, as some varieties of stored seed of $M$. expansa would not germinate in 2016, when Gendall was a visiting researcher at CIP in Lima, Peru (Harriett Gendall, personal communication 2016). Most of the children of the few growers of the crop that Gendall could find in Peru and Bolivia, have little interest in continuing to grow M. expansa, as things stand [3]. It is unclear if the interest in old crops that Gendall has helped to generate in the Peruvian restaurant industry in Lima [3], is sufficient to maintain long term interest in maintaining M. expansa varieties, or sufficiently well-funded and/or includes intent to support much needed work on food safety issues for, and breeding of future varieties of, $M$. expansa. Disease resistance and changing environmental conditions require the development of new varieties if any crop is to have a future, even if only in its home range. There is also other potential research that should be developed with $M$. expansa, that may also contribute to its development as a modern crop $[\mathbf{1}, \mathbf{4}, \mathbf{1 2}]$.

Old crops should be developed for their potential to solve modern environmental problems, including solving climate change, pollution, and water issues in agriculture, and the production of enough nutritious food for earth's increasing population, especially at a time of climate instability. M. expansa appears to repeatedly hit these marks, yet simultaneously fall through financial cracks for research. Though many researchers will put a limited amount of time into research of this kind, even at their own expense, few can maintain this. So, their training in this area often goes nowhere. In addition, unfunded researchers are in general much less competitive than researchers who have been well funded, both for jobs, and to be in position to get support in the future for themselves and others to also do this kind of research. Solving problems for how to keep research going on an ancient crop as promising as M. expansa, may open the door wider for other old/new crops as well.

\section{Abbreviations}

Raised carat " $\wedge$ ”, indicates "to the power of"; Delta-H, is the area enclosed by the striped curves (Figure 2), or integral; DSC, is Differential Scanning Calorimetry; g raw, is the weight of each sample sent to Thailand; g^-1", is the power of per gram; "?Integral, in the DSC printout (Figure 2) is the same as integral, which designates the energy used to melt the starch, prior to normalization with the initial heat capacity, measured in mJs (millijoules); mg starch, measured in mJs (millijoules), $\mathrm{mg}$ starch, is the weight of the dry starch sample prior to suspending it in water for DSC; normalized, is the integral normalized, per 1 gram of starch, utilizing the heat capacity as the reference; 'No.7real' and 'Sr1' (Figure 2), are sample names used in Thailand and have no particular significance here; OSSI, Open Source Seed Initiative; J/g or J*g ${ }^{-1}$, is joules per gram (Figure 2); PV, Peak Viscosity; HPV, (holding) Hot Paste Viscosity; CPV, (final) Cool Paste Viscosity; PT, Pasting Temperature; PTi, Pasting Time; and their derivative parameters; BD, Breakdown = PV $-\mathrm{HPV}$; and SB, Setback = CPV - PV; SEM, is Scanning Electron Microscopy, TEM, is Transmission Electron Microscopy; w/w\%, is the percentage weight of a starch sample that has been suspended in water for DSC.

\section{Acknowledgements}

We would like to thank Harriett Gendall, CIP, and Mahidol University. Also, César Tapia for information on the FAO treaty and Annex I list. Blaine Bartholomew and Jim Persinger are thanked for use of and help with the lyophilizer at SIU-C. Thank you to all of the groups and people who helped Kritzer Van Zant get to and function in Ecuador, where she collected var. $T$, including the US Department of Education, Andes and Amazon Field School and Center for Latin American Studies at Arizona State University, Tod D. Swanson of that program, and our individual colleagues and helpers in Ecuador including Eloisa de la Cruz, Brigida Guachuiun and Lewis Enrique Puente, also QCNE, Homero Vargas of that herbarium, and Abraham Kritzer. Also, thank you to Ryan Bishop of Perten Instruments, Inc., and Jenny, a phone technician for Mettler-Toledo, for assistance in understanding Figure 2 when it was first returned to the US from Thailand. Thank you also to others, too numerous to name.

\section{Contributors}

Kritzer Van Zant collected var. $T$ in Ecuador, grew and harvested the material used for starch testing, lyophilized and air-dried crop material, took the TEM photos of M. jalapa seed starch, weighed and mailed samples to Thailand, and wrote this manuscript. Triwitayakorn received and processed DSC samples, and ran and interpreted the DSC analysis. Lightfoot has served as academic advisor for both Kritzer Van Zant and Triwitayakorn, arranged the collaboration with Mahidol University, and arranged for access to lyophilization facilities, greenhouse space, and sand plots, provided storage space for frozen samples, and assisted with encouragement and advice. 


\section{Conflict of Interest}

As far as we know, there is no conflict of interest in this research for any of the authors.

\section{References}

1. Van Zant MK (2016) History of Mirabilis expansa (Ruiz and Pav.) Standl.; Growth and Use in the Andes. Atlas J. of Bio 236248.

2. Seminario JF, Chalampuente-Flores D, Gendall H, Sørensen M (2019) The Agronomy of Mauka (Mirabilis expansa (Ruíz \& Pav.) Standl.) - A Review J. Plant Gen. Crop Res 1: 1-23.

3. Gendall G, Seminario J, Sørensen M, Theilade I (2019) Unearthing the "Lost" Andean Root Crop "Mauka" (Mirabilis expansa [Ruíz \& Pav.] Standl.). Econ. Bot 73: 443-460.

4. Van Zant MK, Diesburg K, Lightfoot DA (2018) Mirabilis expansa Growth, Yield, and Quality Traits: First US Field Trials for an Ancient, Endangered, Andean Crop. Atlas J. Bio 551-574.

5. Ugent D, Pozorski S, Pozorski T (1982) Archaeological potato tuber remains from the Casma Valley of Peru. Econ Bot 36: 182192.

6. Ugent D, Pozorski S, Pozorski T (1984) New evidence for ancient cultivation of Canna edulis in Peru. Econ Bot 38: 417-432.

7. Chang S-M, Tzeng S-L, Lii C-Y (1983) Isolation and Characterization of the Starch from Four-O'Clock Flower (Mirabilis Jalapa L.) Seed J. Food Sci 48: 1238-1241.

8. Bellido-Valencia O, Huanca-Zúñiga PK, Medina-Marroquín LA (2017) Determination of the Morphology of the Starch Granules and the Optimum Internal Cooking Temperature of Four Andean Crops: Oca (Oxalis tuberosa Molina), Olluco (Ullucus tuberosus Loz), Isaño (Tropaeolum tuberosum Ruiz \& Pavon) and Arracacha (Arracacia xanthorrhiza Bancroft). Acta U. Cibiniensis Series E: Food Technol 21: 2.

9. Aprianita A, Vasiljevic T, Bannikova A, Kasapis S (2014) Physicochemical properties of flours and starches derived from traditional Indonesian tubers and roots. J. Food Sci. Technol 51: 3669-3679.

10. Daniell H, Wurdack K.J, Kanagaraj A, Lee S-B., Saski C, Jansen RK (2008) The complete nucleotide sequence of the cassava (Manihot esculenta) chloroplast genome and the evolution of atpF in Malpighiales: RNA editing and multiple losses of a group II intron. Theor. Appl. Genet 116: 723.

11. Boonchanawiwat A, Sraphet S, Boonseng O, Lightfoot DA, Triwitayakorn K (2010) QTL underlying plant and first branch height in cassava (Manihot esculenta Crantz). Field Crops Res 121: 343-349.

12. Van Zant MK, Banz WJ, Chai H-B, Apgar G, Lightfoot DA (2019) Amino Acid Profiles and Cytotoxicity of Mirabilis expansa (Ruiz and Pav.) Standl.; Baseline Data for A Rare Indigenous Andean Crop. Adv. Nutri. and Food Sci: ANAFS-126.

13. Vivanco JM, Savary BJ, Flores HE (1999) Characterization of Two Novel Type I Ribosome-Inactivating Proteins from the Storage Roots of the Andean Crop Mirabilis expansa. Plant Phys 119.

14. El Bassam N (2010) Handbook of Bioenergy Crops: A Complete Reference to Species, Development and Applications, Earthscan from Routledge, Abingdon, Oxfordshire UK, and NY, NY USA p. 444.

15. Sriroth K, Santisopasri V, Petchalanuwat C, Kurotjanawong K, Piyachomkwan K, Oates CG (1999) Carbohyd Polym 38: 161170.

16. Thai Tapioca Starch Association 2020. Website thaitapiocastarch.org/en/. Date of access: 14Feb2020.

17. OSSI (Open Source Seed Initiative) 2020. Website https://osseeds.org/about/. Date of access: 14Feb2020.

18. Kloppenburg J (2013) Re-Purposing the Master's Tools: The Open Source Seed Initiative and the Struggle for Seed Sovereignty, in Conference Paper \#56 Food Sovereignty: A Critical Dialogue, presented for discussion at the International Conference, Yale University, September 14-15, pp. 8, 24.

Citation: Van Zant MSK, Triwitayakorn K, Lightfoot DA (2020) Explorations into Starch Properties of Mirabilis spp. (Nyctaginaceae); DSC Results for Endangered Andean M. expansa, TEM of M. jalapa Seed. Adv Nutri and Food Scie: ANAFS-172. 